\title{
Aplicación de la terapia EMDR a las conductas autolesivas
}

\author{
Dolores Mosquera \\ Instituto para el Estudio del Trauma y los Trastornos de Personalidad, A Coruña, Spain \\ Colin A. Ross \\ El Instituto Colin A. Ross para el Trauma Psicológico, Richardson, Texas
}

\begin{abstract}
Las autolesiones suelen ser una estrategia de afrontamiento derivada del trauma, que pueden entenderse desde la perspectiva del modelo de procesamiento adaptativo de la información (PAI) y tratarse con terapia de desensibilización y reprocesamiento mediante movimientos oculares (EMDR) (Shapiro, 1995, 2001). Las autolesiones a menudo están conectadas con recuerdos de experiencias adversas y traumáticas en la vida. Identificar y procesar estos recuerdos con terapia EMDR puede poner fin al comportamiento autodestructivo. Además, las autolesiones suelen tener su base en la falta de habilidades de regulación, y estos déficits de habilidades también se pueden abordar en la terapia EMDR. En este artículo, los autores describen estrategias para tratar las autolesiones a lo largo de las 8 fases de EMDR. Aunque no existe un enfoque único que se aplique en todos los casos, el terapeuta debe hacer una historia meticulosa de las autolesiones, sus orígenes históricos, y sus desencadenantes y funciones en el presente para formular un plan de tratamiento. A menudo, según la experiencia de los autores, las autolesiones funcionan como una estrategia de autorregulación que vuelve a disociar las emociones traumáticas de la infancia. Las estrategias de tratamiento para las Fases 3-8 de la terapia EMDR se ilustran a través de ejemplos de casos.
\end{abstract}

Palabras clave: desensibilización y reprocesamiento mediante movimientos oculares (EMDR); autolesiones; disociación; trauma complejo

D e todas las situaciones complejas que podemos encontrar en el contexto terapéutico, las autolesiones y la ideación suicida son dos aspectos que presentan grandes retos para el terapeuta. La autolesión se define aquí como una autolesión física intencional sin intención de morir, que incluye diversos métodos como cortarse, quemarse (cigarrillos, encendedores, etc.), rascarse, golpearse (cabezazos, golpes), morderse, interferir con la cicatrización de heridas, tener sexo de modo imprudente y comer hasta enfermar. El objetivo de este artículo es describir la autolesión como una estrategia de afrontamiento derivada del trauma, que puede entenderse desde la perspectiva del modelo de procesamiento adaptativo de la información (PAI) y que puede entonces tratarse con terapia de desensibilización y reprocesamiento mediante movimientos oculares (EMDR) (Shapiro, 1995, 2001). El modelo PAI es el modelo teórico para la terapia EMDR propuesto por Shapiro (2001). Fue desarrollado para guiar la recogida de historia, la conceptualización de casos, la planificación del tratamiento y las intervenciones, y para predecir el resultado del tratamiento. Según la teoría biopsicosocial de Linehan (1993), una formulación que es directamente relevante para la terapia EMDR, las emociones negativas contribuyen a las autolesiones crónicas en el trastorno límite de la personalidad (TLP) de tres maneras: (a) La reducción de la activación emocional después de la autolesión refuerza negativamente la conducta; (b) la ira, el desprecio y la vergüenza interfieren con que la resolución de problemas y el procesamiento emocional sean saludables; y (c) las emociones relacionadas con la vergüenza conducen directamente al autocastigo o al deseo extremo de esconderse o desaparecer (es decir, perder el conocimiento o morir). Las emociones negativas, en opinión de los autores,

This article originally appeared as Mosquera, D. \& Ross, C. (2016). Application of EMDR Therapy to Self-Harming Behaviors.

Journal of EMDR Practice and Research, 10(2), 119-128. Translated by Miriam Ramos Morrison. 
a menudo, pero no siempre, surgen de experiencias traumáticas no resueltas.

Cuando los comportamientos autodestructivos se basan en la falta de habilidades de regulación, es necesario que el paciente aprenda herramientas y habilidades de afrontamiento adaptativas. En nuestra experiencia, el reprocesamiento de los recuerdos que están en la base de dicha desregulación será crucial en muchos casos, especialmente cuando las emociones, sensaciones, creencias o conductas autolesivas están conectadas con recuerdos traumáticos específicos e información almacenada de manera disfuncional (Mosquera y González, 2014). En este artículo, describiremos cómo explorar, identificar y tratar diferentes tipos de conductas autodestructivas en las diferentes fases de la terapia EMDR.

\section{EMDR Fase 1: Historia}

Uno de los principales problemas que pueden interferir con una adecuada conceptualización del caso es la falta de información sobre las conductas autolesivas. En ocasiones, los clínicos tienen dificultades para explorar estos aspectos del comportamiento del paciente porque piensan que se desestabilizará si lo hacen. Esto es, de hecho, una idea errónea, ya que el clínico sólo puede obtener una comprensión integral y total de los problemas del paciente si explora estos comportamientos. Al comprender la función de las autolesiones y cómo están ayudando a cada paciente, los clínicos podrán diseñar un plan de tratamiento adecuado.

Aunque las conductas autolesivas a menudo se etiquetan como intentos de manipulación o llamadas de atención, debajo de cada una de ellas puede haber problemas muy diferentes que deben identificarse (Mosquera y González, 2014). Pensar en las conductas autolesivas como manipulación o llamadas de atención puede hacer que parezcan un chantaje deliberado y consciente. Como se describe a lo largo de este artículo, autolesionarse tiene muchos motivos diferentes; la manipulación y las llamadas de atención son solo dos de ellos. Los juicios morales negativos sobre las conductas autolesivas por parte de los terapeutas no ayudan a formar una alianza terapéutica en el tratamiento ni a fomentar en el paciente unas conductas y estrategias de afrontamiento más saludables. Para comprender este tipo de comportamiento por parte de los pacientes, debemos explorar la autolesión desde la perspectiva de la historia del paciente. ¿Dónde aprendió este comportamiento? ¿Cuál es su función? ¿Cómo está ayudando al paciente? ¿Qué recursos más sanos faltan en las estrategias de afrontamiento del paciente?

Los motivos habituales para autolesionarse incluyen sentir alivio, "detener el dolor", sentirse vivo o "real", "mostrar cuánto sufro", pedir ayuda, obtener "lo que merezco" (autocastigo), para "limpiarme" (purificación), para asegurarme de que "no estoy soñando" (generalmente relacionado con experiencias disociativas), para "volver a sentir mi cuerpo" y para castigarse a uno mismo o a los demás. Además de las conductas de autolesión más obvias mencionadas, muchos pacientes usan múltiples conductas autodestructivas, como abuso de alcohol o drogas, conductas de riesgo: como conducir de forma temeraria, buscar pelea y sexo impulsivo. A menudo, los pacientes se sienten mal por llevar a cabo estas conductas y esto refuerza el problema, ya que los pacientes se autolesionan de nuevo para alejarse de su sensación de culpa por sus autolesiones previas. Estas conductas se refuerzan a sí mismas porque proporcionan un alivio temporal, disociando a la persona de su dolor y sus conflictos. Sin embargo, la disociación es solo temporal o parcialmente efectiva; tarde o temprano, los recuerdos y sentimientos disociados se entrometen de nuevo y luego tienen que volver a disociarse mediante más autolesiones.

Los pacientes que crecieron sintiendo que nadie se daba cuenta de cómo se sentían, o de que estaban sufriendo, pueden necesitar desesperadamente que el otro les "vea" o les "entienda". A veces, los pacientes intentan hacer que su dolor sea "visible" no solo para los demás, sino también para ellos mismos. En ocasiones, después de muchos intentos fallidos de ser visto o cuidado, la autolesión es la única forma que encuentra la persona para pedir ayuda o conseguirla. Otras veces, autolesionarse puede ser una forma de autocastigarse cuando la persona se siente mal por haberse visto a sí misma como agresiva, equivocada, mala o inadecuada. La autolesión, en nuestra experiencia, puede ser una forma de expresar cuán culpable se siente una persona y puede ser una especie de disculpa o redención (Mosquera, 2008; Mosquera y González, 2014; Ross \& Halpern, 2009).

Algunos ejemplos de pacientes que ilustran estos motivos para autolesionarse serían:

Pasé años pidiendo ayuda directamente, pero solo comenzaron a escucharme cuando comencé a quemarme y morderme los brazos.

Era invisible para mi familia, podía pasarme días en la cama y nadie se daba cuenta. Traté 
de conseguir ayuda muchas veces, pero solo respondieron cuando me arranqué las uñas, me afeité el pelo y me corté el cuerpo.

La exploración de la ideación suicida, de los intentos de suicidio previos y de las conductas autolesivas deberían incluirse en la Fase 1: recogida de historia. Sin embargo, esto no siempre es fácil en casos de trauma complejo y disociación. Puede que la persona no recuerde los detalles de lo que provocó y motivó la conducta autolesiva debido a la amnesia, o que algunas partes no quieran divulgar esta información por diferentes motivos.

Cuando las autolesiones se han vuelto habituales, la conducta puede volverse automática y los pacientes pueden tener dificultades para reflexionar sobre los posibles factores desencadenantes, sentimientos y pensamientos relacionados con las autolesiones. Es importante ayudar a los pacientes a pensar en posibles factores desencadenantes y a que los vean con perspectiva. Siempre debemos explorar lo que sucedió inmediatamente antes de la autolesión y el estado emocional relacionado con el comportamiento. Las respuestas a esta exploración proporcionarán al terapeuta información relevante sobre los recursos que deben instalarse y la psicoeducación que debe introducirse en la Fase 2, así como las posibles dianas que deben abordarse después de la fase de preparación (Mosquera, 2014).

La autolesión debería explorarse en las primeras sesiones. Como se comentó anteriormente, los clínicos deben comprender los problemas subyacentes para crear un plan terapéutico completo e integral. Algunas preguntas útiles para explorar las raíces de las autolesiones, según describe Mosquera (2014), incluyen lo siguiente:

- ¿Cuándo fue la primera vez que te cortaste, te quemaste o te hiciste daño?

- ¿Qué estaba sucediendo entonces?

- ¿Otras personas sabían sobre las autolesiones? Si lo sabían, ¿cómo reaccionaron?

- ¿Cómo te sentiste después?

- ¿Qué piensas de ti mismo justo antes de autolesionarte? ¿Y después?

- ¿Qué emociones o sentimientos están relacionados con esta conducta? ¿Rabia? ¿Tristeza? ¿Vacío? ¿Vergüenza? ¿Ansiedad? ¿Entumecimiento? (El terapeuta puede proporcionar un menú de posibles emociones si el paciente tiene dificultad para identificar el estado emocional que precedió a la autolesión).

- ¿De qué manera te ayudan las autolesiones?
Todas estas preguntas ayudarán a los clínicos a centrarse en la conducta autolesiva y a ver más allá de los síntomas. En el enfoque EMDR de psicoterapia, se considera que los problemas psicológicos están causados principalmente por el efecto acumulativo de experiencias adversas y traumáticas no resueltas (Shapiro, 2001). Las conductas autolesivas están, en muchos casos, relacionadas con la falta de capacidades de regulación y con experiencias adversas. Ross (2012) argumenta que en las personas que son tratadas con EMDR, las emociones y los recuerdos traumáticos con frecuencia están disociados, tanto si existe un trastorno disociativo diagnosticable como si no. Las conductas autolesivas generalmente sirven para disociar las emociones y los conflictos intolerables de la conciencia ejecutiva, por lo que muchas de las conductas se pueden entender como una estrategia de afrontamiento disociativa. La terapia EMDR revierte la disociación reprocesando, desensibilizando e integrando las emociones y los conflictos de los que se ha renegado dentro del modelo PAI.

Los problemas adicionales que se pueden abordar en las fases 1 y 2 de la terapia EMDR para las personas que se autolesionan se enumeran en la Tabla 1.

\section{Entender la conducta autolesiva como un recurso y una estrategia de autorregulación}

Según nuestra experiencia clínica, la mayoría de las veces la autolesión suele llevarse a cabo sin la intención de morir. De hecho, a menudo, la autolesión es una estrategia de prevención del suicidio; no es necesario suicidarse para escapar del dolor intolerable porque está disponible una solución efectiva y temporal. Las diferentes personas recurren a la autolesión por razones muy diferentes. Es importante tener en cuenta que la autolesión es a menudo un recurso de autorregulación. En muchos casos, se produce una paradoja de seguridad, como explicó un paciente:

Siempre dormía con un paquete de cuchillas de afeitar debajo de la almohada. Esto me daba seguridad, porque pensaba que podría usarlas si las cosas se ponían realmente mal.

Las autolesiones pueden ser un mecanismo sustituto a corto plazo para autocalmarse y enraizarse de un modo saludable, y aunque son patológicas pueden ser efectivas. De hecho, el efecto de la autolesión puede ser tan inmediato que puede ser difícil para la persona usar otras estrategias que sean efectivas, pero que requieran un poco más de tiempo y esfuerzo. Cuando un paciente se siente abrumado por el dolor emocional, autolesionarse puede ser una estrategia distractora; 
1. Familiarizarse con el patrón de comportamiento asociado con la autolesión. Puede ser útil preguntar cuándo sucede, cómo sucede, dónde sucede y por qué sucede.

2. Descubrir el patrón de autolesión (organizado, desorganizado, premeditado, impulsivo).

3. Si los pacientes usan objetos para autolesionarse, descubrir qué se está utilizando, cómo se obtienen estos objetos, si se limpian y/o desinfectan, dónde se suelen guardar, si tienen algún significado o no, y las razones para elegirlos, tanto inicialmente como en la actualidad.

4. Explorar el contexto en profundidad (privado, público...).

5. Averiguar si los pacientes habitualmente se autolesionan solos o si alguna vez lo han hecho en presencia y/o compañía de otras personas.

6. Explorar la extensión de la lesión y los puntos del cuerpo que los pacientes tienden a dañar para buscar ayuda médica cuando la situación lo requiera. Algunos cortes necesitan puntos y no sanarán fácilmente sin una intervención. Si los pacientes no acuden al médico, pueden surgir otros problemas, como por ejemplo, infecciones, que en casos extremos pueden tener un resultado muy negativo, como la amputación de un pie o una mano.

7. Ayudar a los pacientes a identificar los diferentes estados emocionales que preceden y siguen a cada episodio. Explorar cómo se sienten antes, durante y después de las autolesiones.

8. Diferenciar entre autolesión e intentos de suicidio. Son cuestiones muy diferentes, con motivaciones diferentes, y cada una tiene que ser tratada específicamente.

9. Averiguar los posibles desencadenantes de la autolesión con la intención de facilitar y proponer mejores alternativas de adaptación a corto y largo plazo.

10. Averiguar cómo viven los pacientes con sus lesiones: ¿Las ocultan? ¿Están avergonzados? ¿Las muestran? ¿Se jactan de ellas? Esto proporcionará información significativa sobre la motivación y el motivo del comportamiento.

11. Confrontar el pensamiento dicotómico, ayudar a los pacientes a tomar posiciones intermedias y ampliar la visión global de diferentes situaciones.

12. Ayudar a los pacientes a identificar sus respuestas emocionales, y cómo su forma de percibir e interpretar las diferentes situaciones puede influir en estas respuestas.

13. Ayudar a los pacientes a verbalizar diferentes estados emocionales para que puedan expresar sus emociones con palabras y, sobre todo, para que puedan identificar las emociones que les suelen llevar a autolesionarse.

14. Hacer sugerencias que los pacientes puedan implementar para manejar la angustia emocional.

15. Desarrollar planes de acción de contingencia para situaciones críticas que tienden a "activar" a los pacientes y hacerles que piensen sobre las autolesiones. Esto debe hacerse independientemente de las razones por las que se autolesionan, porque debemos recordar que algunos lo hacen para aliviarse, otros para "volver a la realidad", otros para sentirse vivos y otros para "conseguir lo que se merecen".

16. Evitar reacciones de alarma excesiva, mantener la calma y concentrarse en las soluciones, independientemente de la gravedad del comportamiento y/o lesión.

17. Profundizar en las razones que preceden a cada episodio de autolesión, sin entrar en preguntas que puedan parecerles morbosas a los pacientes. Es importante explorar la autolesión en profundidad y mostrar interés con tacto, sin ser intrusivo. 
los pacientes a menudo sienten que el dolor físico es mucho más tolerable que el dolor psicológico. La autolesión también puede ser una forma de disociar un sentimiento o recuerdo perturbador o de detener un episodio de despersonalización. Cuando las personas se sienten vacías, planas y entumecidas, pueden usar la autolesión para "sentirse vivas" o "sentirse reales", como lo describe un paciente:

En mi caso, la autolesión tiene un objetivo específico: sentirme mejor. Cada vez que me corto, pienso que no lo volveré a hacer. . . Sé que no es normal, pero es como si no pudiera evitarlo. No siempre me corto, pero lo pienso casi todos los días. A veces no lo hago, y solo hago otras cosas, pero hay momentos en los que el dolor es tan fuerte, tan intenso y tan brutal que no puedo soportarlo más. Es justo en esos momentos cuando me hago daño. Justo después de cortarme, me siento bien, aliviado.

A veces entro en trance. . Siento que me estoy volviendo loco, que no existo, que no soy real, es como si estuviera muerto. . . A veces me quemo solo para comprobar si todavía estoy vivo y aún siento algo.

Si los pacientes han sido castigados por sentir o expresar una determinada emoción, tenderán a hacerse lo mismo cuando sean adultos: "Te castigas por fuera, tratando de matar al monstruo que está dentro". La autolesión se ha convertido en un recurso complejo que ahora, en la edad adulta, parece tener más costo que beneficio. Los pacientes que se autolesionan tienden a ver el beneficio, pero no el costo.

Los pacientes a menudo buscan ingresar en un hospital cuando se dan cuenta de que sus cortes están aumentando hasta el punto de que ponen en riesgo la vida, lo que coincide con que no quieran morir y con su uso de las autolesiones como estrategia de prevención del suicidio.

\section{Fase 2: Estabilización}

Cuando la autolesión se basa en la falta de habilidades de autorregulación, como suele ser el caso, es necesario ofrecer a los pacientes herramientas de afrontamiento más sanas, además de trabajar en los recuerdos que son la base de dicha desregulación. Para organizar una Fase 2 adecuada, los clínicos deben comprender los problemas subyacentes. En la mayoría de los casos, la instalación de recursos y el reprocesamiento de las experiencias de vida adversas relacionadas con autolesiones serán suficientes para estabilizar al paciente. Pero esto solo tendrá éxito si hacemos una recogida de historia que nos permita obtener un conocimiento profundo de cada caso.

Se recomienda el desarrollo e instalación de recursos (DIR) para expandir las respuestas de afrontamiento en la Fase 2 (Korn y Leeds, 2002; Leeds, 2009a, 2009b). Linehan (1993) ha proporcionado numerosas estrategias de tratamiento para la autolesión dentro de su terapia dialéctica conductual. Estas pueden incorporarse en las primeras dos fases de EMDR, tanto si el paciente cumple con todos los criterios de un TLP como si no. Los clínicos también deben tener en cuenta que no siempre son necesarios ni están recomendados los procedimientos de estabilización prolongados. Es importante adaptarse a las necesidades de cada paciente y no alarmarse por la gravedad de los síntomas.

El siguiente caso ilustra cómo, en un individuo con un buen funcionamiento y sin una comorbilidad extensa y grave, se puede lograr la estabilización sin una preparación extensa, y el tratamiento puede avanzar con bastante rapidez hacia las fases de desensibilización de EMDR.

\section{Ejemplo de caso 1: No veo salida}

Martha, una mujer de 60 años, acude a terapia después de muchos años de tratamiento. El tratamiento se había centrado principalmente en la reducción de los síntomas mediante medicación y frecuentes ingresos hospitalarios (muchos de ellos duraron más de 3 meses).

En la primera sesión, la paciente dice: "Mi problema es que mi padre me violó cuando tenía 7 años".

Revela numerosos sucesos traumáticos en los que estuvo directamente involucrada y muchos otros en los que fue testigo de cómo sus hermanos fueron maltratados y abusados. Le vienen constantemente flashbacks de episodios traumáticos e intenta hacerlos desaparecer autolesionándose. Ella afirma que autolesionarse suele ser eficaz, pero que hay momentos "cuando no ha sido suficiente" y es cuando se quiere suicidar. Al hacer diana en sus recuerdos traumáticos, comenzando con las imágenes más intrusivas, se estabilizó. Su caso muestra cómo solo la supresión del afecto y la reducción de los síntomas, sin desensibilizar los recuerdos y sentimientos traumáticos subyacentes, no conduce a la estabilización y menos aún a la resolución. La ineficacia de los abordajes anteriores se identificó en las dos primeras fases de la terapia EMDR, y pudo proceder al reprocesamiento activo y la desensibilización sin que hiciese falta una estabilización extensa.

\section{Fases 3-7}

Una de las dificultades que los clínicos pueden encontrar con los pacientes que se autolesionan o que tienen 
ideación suicida, es que puedan tolerar la intensidad emocional del dolor. Los pacientes que carecen de capacidad de autorregulación, a menudo tienen miedo de sus propias reacciones y necesitan una sensación de seguridad y contención por parte del clínico. Muchos pacientes no aprendieron a autorregularse porque sus cuidadores se encontraban abrumados por sus propias emociones. El contexto terapéutico puede convertirse en una nueva experiencia de aprendizaje para dichos pacientes.

En la mayoría de los casos, se puede usar un protocolo EMDR estándar, siendo los casos disociativos complejos una excepción. En casos disociativos complejos, el trabajo con el sistema interno y otras técnicas de tratamiento del trastorno de identidad disociativo (TID) pueden ser necesarias en las fases de estabilización de EMDR (Forgash y Copeley, 2008; Gonzalez y Mosquera, 2012; Ross, 1997, 2015; Ross y Halpern, 2009). Sin embargo, según nuestra experiencia clínica, una vez que se complete este trabajo, se puede emplear el protocolo estándar para las Fases 3-7.

Uno de los aspectos de las Fases 3-7 que podría dar lugar a confusión con respecto al uso de los procedimientos de terapia EMDR estándar, es el tipo de asociaciones que pueden ocurrir. Por ejemplo, la ideación suicida puede activarse durante el reprocesamiento, pero esto no es necesariamente un efecto adverso y puede manejarse. Cuando las personas están acostumbradas a pensar en la autolesión como solución, tan pronto como sientan emociones que les abrumen, pensarán en "hacerse daño". Esto no implica que tengan un plan o deseos de morir, es simplemente el modo en el que suelen pensar. Desde su perspectiva, tiene sentido que piensen en autolesionarse porque se ha convertido en una estrategia de afrontamiento habitual, y durante el reprocesamiento se activará este vínculo entre las emociones y las autolesiones. Si seguimos adelante, empleando un entretejido y manteniendo la calma y la seguridad, esto se procesará y finalmente llegarán a la asociación adaptativa. Los entretejidos estándar como "este es un pensamiento que te viene a menudo a la mente, está bien, sigue con eso" puede ser útil para contener el procesamiento y permitir que tenga lugar el procesamiento adaptativo de la información.

Otra posible complicación que puede afectar a los clínicos es la posibilidad de que un paciente se active después de realizar un trabajo de trauma y recurra a las autolesiones.

Aunque esto puede suceder, no es probable si el clínico está familiarizado con el trauma complejo. Uno de los principales problemas está relacionado con un dilema habitual que ocurre al hacer trabajo de trauma, que es la ambivalencia del paciente. Una parte del paciente puede querer hacerlo (para deshacerse de los síntomas que experimenta como intrusivos), mientras que otra parte puede no sentirse lista para hacer este trabajo. Un terapeuta en sintonía estará atento a este conflicto, ayudando a los pacientes a identificar sus límites y no hacer más trabajo del que están preparados para hacer. Esta intervención básica será crucial para que las futuras intervenciones sean seguras.

En casos más graves y complejos, puede ser necesario trabajar con el niño interior, como se ilustra en el ejemplo de caso 2. En este caso, no había un trastorno disociativo, pero había un niño interior disociado, y el yo adulto había estado evitando fóbicamente los sentimientos de ese niño interior. El terapeuta procede con una intervención similar a la que se haría en un trastorno disociativo para aumentar la comunicación y la cooperación entre la paciente y su propio trauma no resuelto, que está contenido dentro de su estado del yo del niño interior. La paciente debe comenzar a y esto de nutrirse?? no es de alimentacion esto?? curarse y cuidarse a sí misma a través de la visualización del cuidado de su niño interior. El terapeuta hace esto sabiendo que el estado del niño interior no es una parte de la personalidad con perspectiva en primera persona.

\section{Ejemplo de caso 2: Trabajo de autocuidado}

Después de casi 2 años de trabajo de estabilización basado principalmente en psicoeducación, el terapeuta está tratando de procesar un recuerdo traumático. El proceso parece bloqueado, y el terapeuta cree que esto podría estar causado por creencias negativas directamente relacionadas con el procedimiento, como "soy incapaz de explicar lo que siento" y "lo estoy haciendo mal". La paciente carece de habilidades de regulación emocional y sus emociones la abruman fácilmente. Este ejemplo no trata directamente las autolesiones; en cambio, las dianas principales son las creencias negativas nucleares sobre sí misma y la falta de estrategias calmantes que generan sus conductas autodestructivas:

T: (después de la estimulación bilateral o EBL): ¿Te viene algo diferente? Por un momento dejaste de mover los ojos.

C: No sé.

T: ¿Qué notas ahora?

C: Lo mismo: mucha angustia. . . No lo sé ... mucha ... Estoy tomando tantos medicamentos que no me salen las palabras. Noto sensaciones, pero no tengo las palabras para explicarlas. 
T: No necesitas decirme todo lo que te viene a la mente o tener la palabra exacta para describirlo, solo necesito una descripción aproximada. Vamos a hacer una tanda más larga, ¿de acuerdo?

C: Vale. [EBL]

T: ¿Qué notas ahora?

C: Noto angustia. [EBL]

T: ¿Qué te llega ahora?

C: Estoy perdiendo la concentración. [EBL]

La paciente tiene dificultades para seguir los movimientos oculares, por lo que cambiamos a tapping.

$\mathrm{T}$ : ¿Qué te viene ahora?

C: Todavía noto mucha angustia y. . . jargh! Esto es muy difícil, no puedo. [EBL]

T: ¿Qué notas?

C: Me estoy poniendo aún más ansiosa porque no me puedo concentrar en nada. Me siento inútil, ni siquiera puedo hacer esto.

T: Mírame un momento [la paciente mira]. ¿Qué crees que deberías hacer ahora?

C: No lo sé. . .

T: No tienes que hacer nada ahora, lo estás haciendo bien. Nos estamos centrando en una sensación física que notas habitualmente, solo queremos aliviarla un poco. Tu mente puede ir a donde necesite ir. No hay una forma incorrecta de hacer esto. [EBL]

T: ¿Qué te viene?

C: Creo que si me muriera, muchas personas se sentirían aliviadas.

El proceso no está funcionando bien. Incluso la palabra "alivio" que dijo el terapeuta activa pensamientos suicidas. Todo lo positivo parece convertirse en negativo. [EBL]

T: ¿Qué te viene ahora?

C: Que solo me quiero morir.

La información verbal y no verbal no encajan. El terapeuta comprueba con la paciente.

T: ¿Cómo está la presión en el pecho?

C: Igual.

T: Abre los ojos [la paciente abre los ojos]. . . Dices que la presión en el pecho está igual, pero tu cuerpo ha cambiado drásticamente. ¿Puedes comprobar y ver si estás notando alguna sensación que pueda ser diferente?
C: Sí.

T: ¿Qué notas?

C: Está un poco más ... más ... un poco más ... más ... No sé ... más ... relajado.

Incluso cuando la EBL está teniendo un efecto positivo y relajante, las tendencias autodestructivas de la paciente son muy intensas. La paciente tiene dificultades para notar mejoría y tiende a enfocarse en aspectos negativos.

T: Estás haciendo un gran esfuerzo. Aunque te sientes mal, lo sigues intentando.

La paciente se emociona (lágrimas).

T: Parece que lo que estoy diciendo te emociona. ¿Por qué?

C: Porque me entiendes. Siento que me valoras. Tú eres la única persona que aprecia lo que hago.

Siguiente sesión. Después de las dificultades para reprocesar un recuerdo durante la última sesión, el terapeuta intenta hacer DIR.

T: Piensa en un momento en el que te sentiste realmente bien.

C: Cuando me sentí realmente bien. . . [se toma mucho tiempo para pensar, largo silencio].

$\mathrm{T}$ : O cuando estuviste satisfecha por algo que hiciste bien.

C: Es difícil para mí sentirme bien y pensar que hago algo bien.

T. ¿Recuerdas alguna vez cuando sucedió esto? Intenta pensar en una situación, sería muy útil.

C: Estoy bloqueada.

Cuando los patrones de autocuidado están invertidos, las cosas pueden evolucionar de forma inversa. Intentar encontrar un recurso hace que se sienta peor porque le hace darse cuenta de cuántas cosas le faltan.

T: ¿Es por la pregunta que te hice?

C: Sí, porque no recuerdo ninguno.

$\mathrm{T}$ : Ok, ¿entonces no puedes pensar en nada positivo?

C: No.

T: ¿Qué sería lo suficientemente positivo para ti? ¿Podrías intentar pensar en algo?

C: No sé cómo. 
La paciente tiene una visión extremadamente negativa de sí misma, y esto interfiere con cualquier intervención que se intenta en terapia. Aunque ha aprendido muchas habilidades de regulación emocional y muchas habilidades nuevas, no puede usarlas para mejorar.

C: No sé, siempre dependo de lo que dicen los demás para valorarme. No puedo hacerlo sola, no sé por qué. . . Debería aprender a hacer eso, a valorarme a mí misma.

T: ¿Y cómo podrías aprender eso? [Tratando de hacerla pensar]

C: No sé, no tengo ni idea. Nunca lo he hecho.

$\mathrm{T}$ : ¿Dónde aprendiste a no valorarte a ti misma? ¿Podrías pensar en eso?

C: No sé. . Creo que nunca me he valorado.

$\mathrm{T}:$ ¿Y cuando eras pequeña?

C: No.

La paciente no se da cuenta de la conexión entre el rechazo y la hostilidad en su entorno familiar infantil y su actitud negativa hacia ella misma. Para trabajar con reparar el patrón de autocuidado, la diana será la imagen de la niña que era cuando aprendió el patrón. La diana será una fotografía.

T: Cuando miras fotos tuyas de cuando eras pequeña, ¿qué sientes?

C: Tristeza. . . todo el mundo dice que le encantaría volver a la infancia. Yo no, siento que fue triste. . No me gusta nada.

$\mathrm{T}$ : ¿Tienes fotos de cuando eras pequeña?

C: Muy pocas. . Tengo una de cuando era pequeña. Se la cogí a mi madre.

T: ¿Qué foto cogiste?

C: Una de cuando tenía 1 año aproximadamente. Llevo puesto un vestido, uno corto, con el que se pueden ver los pañales.

$\mathrm{T}$ : ¿Por qué elegiste esa imagen?

C: Porque tenía una mirada muy dulce. Me gusta su mirada.

T: Cuando miras esta imagen, ¿qué sientes hacia ti misma?

C: Veo a una niña dulce, una niña triste, no sé. . . parece desprotegida. Tengo ganas de abrazarla.

En este punto, la paciente no presenta una fobia disociativa hacia esta parte emocional. Desde su yo adulto, surge espontáneamente la tendencia a cuidar de esta niña pequeña.
No existen barreras significativas entre el estado adulto y el estado infantil. Cuando mira a la niña no se siente abrumada por las emociones. No hay elementos que necesiten una intervención especifica, por lo que podemos enfocarnos en reforzar esta tendencia positiva que aparece.

T: Sería genial si pudieras. . Creo que muchas de las cosas que no entiendes provienen de allí, de esta sensación que ya tenías cuando eras muy pequeña. Si pudieras sostener a esa niña pequeña ahora, ¿qué harías?

C: Abrazarla y acurrucarla.

T: ¿Qué le dirías? Intenta imaginar a esa niña pequeña. Mira a esa niñita, mírala a los ojos y dime ¿qué dirías?

C: Que me ocuparé de ella, que no va a pasarle nada.

T: Cierra los ojos y nota eso, piensa en eso. [EBL]

T: ¿Qué te llega?

C: Es como si quisiera llorar.

$\mathrm{T}$ : Ok, sigue con eso y llora si quieres. [EBL]

T: ¿Qué te llega ahora?

C: Tengo ganas de abrazarla y protegerla.

T: Ok, déjaselo saber. Lo que ella no sabía de niña y lo que ahora sabes de adulta: que puedes protegerla. [EBL]

T: ¿Qué te llega ahora?

C: Le digo que la abrazaré y le contaré cuentos.

T: Sigue con eso. [EBL]

$\mathrm{T}:$ ¿Y ahora?

C: Que la protegeré, que no la dejaré sola.

T: Ok, hazle saber eso; es importante. ¿Qué te llega?

C: Que independientemente de lo que haga, siempre la apoyaré.

T: Sigue con eso. [EBL]

$\mathrm{T}:$ ¿Y ahora?

C: Que siempre puede contar conmigo.

T: Nota eso. [EBL]

$\mathrm{T}:$ ¿Y ahora?

C: Que no la molestaré.

T: Eso es muy importante. [EBL]

C: Le permitiré que sea ella misma.

T: Solo nótalo. . . estas son cosas muy importantes. [EBL]

T: ¿Qué te llega ahora?

C: Le digo que podrá hacer lo que quiera. [EBL] 
T: ¿Y ahora?

C: Trataré de hacerla feliz.

T: Muy importante, nota eso. [EBL]

T: ¿Qué te llega?

C: Que ella será lo más importante de mi vida.

Después de todos estos elementos positivos, aparece algo de perturbación. Exploramos si proviene del estado del yo infantil o del yo adulto.

T: ¿Qué te llega ahora?

C: Estoy un poco alterada.

T: ¿Esta perturbación es tuya o es de ella?

C: Mía.

T: Sigue con eso. [EBL]

T: ¿Qué te llega ahora?

$\mathrm{C}$ : Esto es muy fuerte.

T: ¿Qué es?

C: Esta sensación de palpitación.

T: Sigue con esa sensación. [EBL]

T: ¿Qué te llega ahora?

C: Sigue siendo muy fuerte.

$\mathrm{T}$ : Ok, sigue con eso. [EBL]

$\mathrm{T}:$ ¿Y ahora?

C: Estoy alterada, es como si no pudiera respirar bien.

$\mathrm{T}$ : ¿Puedes seguir?

La paciente asiente.

T: Respira profundamente, abre los ojos. Cuando piensas en esta niña y en todas las cosas que le has contado, esas cosas tan importantes, ¿qué estás pensando ahora? ¿Cómo te sentiste al poder decirle esas cosas a esta niña pequeña?

C: En cierto modo fue bueno, pero yo no tuve nada de eso.

$\mathrm{T}:$ ¿Es por eso que te alteraste?

\section{La paciente asiente.}

$\mathrm{T}$ [modelado]: Puedes intentar decirle a esta niña que, aunque estaba tan falta de afecto, ahora eres una adulta y puedes cuidarla.

C: No lo sé, porque sentí mucha responsabilidad.
$\mathrm{T}$ : ¿Responsabilidad?

C: Sí, eso creo.

T: ¿Qué significa eso?

C: Estaba pensando: "Estoy diciendo esto, ¿pero podré hacerlo realmente?"

T: Eres muy responsable, ¿qué piensas?

C: No sé, no tengo hijos porque no quisiera que ningún niño pasara por lo que pasé yo, ni tuviera una infancia tan triste como la mía, no lo sé.

Cuando la paciente tiene dificultades para imaginarse a sí misma desempeñando un papel de cuidadora adecuada con la niña pequeña, ayudamos a la paciente a conectarse con el papel de cuidador en otras áreas de su vida y luego "cambiar" este papel hacia ella misma. Muchas personas gravemente traumatizadas cuidan adecuadamente a otras personas, incluso cuando no se cuidan en absoluto.

C: No sé si podría tener un hijo y hacerle feliz.

T: ¿Cómo conectas con tus sobrinos? [El terapeuta sabe que la adoran]

C: Bien, pero son mis sobrinos, no están conmigo todo el tiempo.

T: Estoy preguntando cómo conectas con ellos, ¿̇cómo se sienten cuando están contigo?

C: Bien, sí, pero son mis sobrinos. . No los tengo todo el día.

T: Pero te tienes a ti misma todo el día.

C: Sí.

$\mathrm{T}$ : $\mathrm{Y}$ es importante que aprendas a cuidarte, a valorarte a ti misma... a darte lo que te faltó cuando eras niña. Sin embargo, ahora te tienes a ti y estás haciendo muchas cosas para cuidarte.

C: Sí, es verdad, ahora hago muchas cosas para protegerme, lo noto.

T: Sí, por eso te digo esto, porque ahora haces cosas para cuidarte y protegerte, así que creo que puedes comunicar estas cosas a la niña. Creo que es importante "curar" esa tristeza de otras etapas de tu vida que te ha acompañado durante toda la vida.

T: Pareces más tranquila ahora.

C: Sí.

T: ¿Por qué?

C: No lo sé, porque me tranquiliza escuchar lo que estás diciendo.

$\mathrm{T}$ : ¿Tiene sentido? 
La paciente asiente.

T: Creo que es importante trabajar con problemas del pasado, ver que sientes muchas sensaciones que no entiendes del todo, poder sanar y aprender que te tienes a ti misma, aprender a valorarte a ti misma. ¿Te parece bien?

La paciente asiente.

T: ¿Tiene sentido?

C: Sí.

T: La próxima vez que nos veamos, le darás un abrazo a esta niña pequeña.

C: Vale.

$\mathrm{T}$ : ¿Cómo te sientes ahora?

C: Bien.

T: ¿Seguirás protegiéndote?

C: Sí.

T: Te has dado cuenta de que esto es importante, ¿verdad?

C: Sí.

T: Estoy contento, realmente contento. No esperaba que dijeras esto por ahora.

\section{La paciente asiente.}

T: Estaba esperando que te dieras cuenta de esto.

C: Sí [sonríe]. . . Estamos progresando.

T: Sí.

\section{Siguiente sesión}

En la siguiente sesión, después de años de agradar a otros para ser aceptada, comienza a establecer límites por primera vez, después de que el terapeuta hubiera trabajado en este tema durante años. Ella cambió su actitud sumisa por una más segura. Esto también se hace obvio en su lenguaje corporal; tiene una postura corporal erguida.

C: [Explicando lo que le dijo a una persona que dependia de ella.] Entonces le dije: "Hoy hablaremos sobre mi enfermedad. Me pongo muy ansiosa y muy triste cuando me cuentas tus problemas todo el tiempo. Esto puede ser sano para ti, pero no es sano para mí. Así que debemos llegar a un punto intermedio. Esta debería ser una relación sana para ambas".

T: iiMuy bien!!! Muy bien, Susan.

C: Te ayudaré tanto como pueda, manteniendo estos límites. Ella reaccionó bien.
T: Fuiste clara, dijiste lo que pensabas

C: Sí, también le dije: "Si sigo tolerando esto, me voy a poner muy enferma y no podré ayudarte más". Entonces tendría que alejarme de ti, y la relación terminaría, no podría ayudarte ni a ti ni a nadie más, y estaría enferma”. Y ella dijo:” ¡No, no, no quiero eso!”. $\mathrm{Y}$ eso fue todo.

T: Has lidiado muy bien con esto y ves que ella reaccionó bien. Lo otro sería peor para ambas. Estás siendo un buen ejemplo para ella.

La paciente ahora puede centrarse en el bienestar y en los aspectos positivos de sí misma. Parece que no necesita tanto refuerzo del terapeuta como antes, y explica espontáneamente sus logros. Está más activa y de buen humor. La intervención previa con el procedimiento de autocuidado ha cambiado cómo se siente y cómo actúa. Es como si esta intervención hubiera sido un punto de inflexión que permitió a la paciente utilizar todas las habilidades que había aprendido en 2 años de terapia. A partir de este momento, fue posible trabajar con el protocolo estándar en temas traumáticos. Incluso podía describir la lista de los 10 acontecimientos traumáticos principales sin sentirse abrumada como antes.

Su patrón de autocuidado anterior, que no era sano, estaba bloqueando la mejoría y, en este caso, no fue complicado convertir el autocuidado en un patrón positivo y saludable. En otros casos, será necesario hacer intervenciones específicas para superar las fobias disociativas, integrar información sana sobre apego, desarrollar diferenciación o regular emociones. A veces, se necesitan varias sesiones para lograr cambios, y el autocuidado sano debe entretejerse constantemente en muchas otras intervenciones.

\section{Identificación de posibles dianas para la desensibilización}

Una identificación y reprocesamiento adecuados de recuerdos traumáticos y dilemas internos no resueltos pueden poner fin a la conducta autolesiva. Por lo general, la diana no será la conducta autolesiva sino las circunstancias que rodearon la primera vez que ocurrió, las creencias negativas asociadas con la conducta y los recuerdos que puedan identificarse a través de un puente afectivo. Algunos ejemplos de posibles dianas (Mosquera, 2014) son los siguientes:

- Las emociones, sensaciones, creencias y experiencias de recuerdos intrusivos antes de autolesionarse a menudo se conectan con acontecimientos biográficos específicos. 
- La diana no sería la conducta autolesiva en sí misma a menos que la conducta diese lugar a consecuencias terribles (por ejemplo, que el paciente acabe en una silla de ruedas y tenga pensamientos repetitivos sobre lo que hizo).

- Las circunstancias que rodearon la primera vez que el paciente se autolesionó.

- El origen de las creencias negativas asociadas con las autolesiones.

- Recuerdos específicos relacionados con los disparadores actuales; estos recuerdos se pueden identificar a través de un puente afectivo.

- Sensaciones somáticas que activan las autolesiones (a veces, no hay recuerdos cognitivos o visuales, sino solo sensaciones insoportables).

- Estados emocionales asociados con las autolesiones (sentirse vacío, inútil o culpable).

- Reacciones idealizadas de los miembros de la familia (la primera vez que el paciente ingresó en el hospital después de autolesionarse y luego vio preocupación en los rostros de sus seres queridos o les oyó expresar amor).

\section{Conclusión}

Al trabajar con conductas autolesivas, es crucial explorar e intervenir más allá del propio síntoma. Las emociones, sensaciones, creencias y recuerdos intrusivos que ocurren antes de autolesionarse a menudo están relacionados con acontecimientos biográficos específicos que deben explorarse y abordarse. Cuando las autolesiones se basan en la falta de habilidades de autorregulación, es necesario ofrecer a los pacientes herramientas de autorregulación, además de trabajar en los recuerdos que están en la base de dicha autorregulación malsana.

Un patrón disfuncional de autocuidado aprendido en la infancia a menudo continúa hasta la edad adulta. Cambiar patrones con terapia EMDR requiere una intervención dirigida y no se logra únicamente procesando recuerdos específicos o acontecimientos traumáticos. Los pacientes deben aprender a verse a sí mismos a través de unos ojos que sean diferentes de los de sus cuidadores principales abusivos, con los que se han identificado. Deben prestar atención a sus necesidades y aprender a cuidar de sí mismos y a ser cuidados por los demás de una manera equilibrada y saludable

\section{Referencias}

Forgash, C., \& Copeley, M. (2008). Healing the heart of trauma and dissociation with EMDR and ego state therapy. New York, NY: Springer Publishing.
Gonzalez, A., \& Mosquera, D. (2012). EMDR and dissociation: The progressive approach. Madrid, Spain: Ediciones Pléyades.

Korn, D. L., \& Leeds, A. M. (2002). Preliminary evidence of efficacy for EMDR resource development and installation in the stabilization phase of treatment of complex posttraumatic stress disorder. Journal of Clinical Psychology, 58(12), 1465-1487.

Leeds, A. M. (2009a). A guide to the standard EMDR protocols for clinicians, supervisors, and consultants. New York, NY: Springer Publishing.

Leeds, A. M. (2009b). Resources in EMDR and other trauma-focused psychotherapy: A review. Journal of EMDR Practice and Research, 3(3), 152-160. http: / / dx.doi .org/10.1891/1933-3196.3.3.152

Linehan, M. (1993). Cognitive-behavioral treatment of borderline personality disorder. New York, NY: Guilford Press.

Mosquera, D. (2008). La autolesión: el lenguaje del dolor [Selfharm: The language of pain]. Madrid, Spain: Ediciones Pléyades.

Mosquera, D. (2014). Suicide, self-harm and EMDR. Paper presented at the 2014 EMDRIA International Association Conference, Denver, CO.

Mosquera, D. (2015). Rough diamonds. A glimpse into borderline personality disorder. North Charleston, SC: Createspace Independent Platform.

Mosquera, D. y Gonzalez, A. (2014). Borderline personality disorder and EMDR therapy. Madrid, Spain: Ediciones Pléyades.

Ross, C. A. (1997). Dissociative identity disorder: Diagnosis, clinical features, and treatment of multiple personality (2nd ed.). New York, NY: Wiley.

Ross, C. A. (2012). EMDR is based on a trauma-dissociation model of mental disorders. Revista Iberoamericana de Psicotraumatología y Disociación, 3, 1-17.

Ross, C. A. (2015). When to suspect and how to diagnose dissociative identity disorder. Journal of EMDR Practice and Research, 9, 114-120.

Ross, C. A., \& Halpern, N. (2009). Trauma model therapy: A treatment approach for trauma, dissociation, and complex comorbidity. Richardson, TX: Manitou Communications.

Shapiro, F. (1995). Eye movement desensitization and reprocessing: Basic principles, protocols, and procedures. New York, NY: Guilford Press.

Shapiro, F. (2001). Eye movement desensitization and reprocessing: Basic principles, protocols, and procedures (2nd ed.). New York, NY: Guilford Press.

Agradecimientos. Los autores quieren dedicar este artículo a la memoria de Carol York, 16 de febrero, 1950-23 de octubre, 2015. Carol hizo innumerables contribuciones al campo de EMDR durante más de dos décadas.

La correspondencia relacionada con este artículo debe dirigirse a Dolores Mosquera, Instituto para el estudio del trauma y los trastornos de personalidad, General Sanjurjo, 5, 15006, A Coruña, Spain. E-mail: doloresmosquera@gmail.com 